\title{
Cetuximab promotes anticancer drug toxicity in rhabdomyosarcomas with EGFR amplification in vitro
}

\author{
YUKI YAMAMOTO $^{1 *}$, KAZUMASA FUKUDA $^{2 *}$, YASUSHI FUCHIMOTO ${ }^{4 *}$, \\ YUMI MATSUZAKI ${ }^{3}$, YOSHIRO SAIKAWA ${ }^{2}$, YUKO KITAGAWA ${ }^{2}$, \\ YASUHIDE MORIKAWA $^{1}$ and TATSUO KURODA ${ }^{1}$ \\ Departments of ${ }^{1}$ Pediatric Surgery, ${ }^{2}$ Surgery and ${ }^{3}$ Physiology, Keio University School of Medicine, \\ Tokyo $160-858 ;{ }^{4}$ Division of Surgery, Department of Surgical Subspecialities, \\ National Center for Child Health and Development, Tokyo 157-8535, Japan
}

Received January 15, 2013; Accepted April 2, 2013

DOI: $10.3892 /$ or.2013.2588

\begin{abstract}
Overexpression of human epidermal growth factor receptor (EGFR) has been detected in various tumors and is associated with poor outcomes. Combination treatment regimens with EGFR-targeting and cytotoxic agents are a potential therapeutic option for rhabdomyosarcoma (RMS) with EGFR amplification. We investigated the effects of combination treatment with actinomycin D and the EGFR-targeting agent cetuximab in 4 RMS cell lines. All 4 RMS cell lines expressed wild-type K-ras, and 2 of the 4 overexpressed EGFR, as determined by flow cytometry, real-time PCR and direct sequencing. Combination of cetuximab and actinomycin D was highly effective, synergistically inhibiting cell growth with a combination index of less than 1 . Moreover, combination treatment with these two reagents increased the rate of apoptosis in EGFR-positive cells. Cetuximab has antitumor activity in EGFR-amplified RMS cells when combined with antitumor reagents, indicating that cetuximab is a potential therapeutic reagent for RMS with EGFR amplification.
\end{abstract}

\section{Introduction}

Rhabdomyosarcoma (RMS) is the most common pediatric soft tissue sarcoma. RMS comprises 7-8\% of all solid malignant tumors in children and represents approximately two-thirds of all infant sarcomas diagnosed (1). There are 2 distinct histopathological subtypes of this malignancy, embryonal RMS (ERMS) and alveolar RMS (ARMS) (2). In contrast to ERMS, ARMS is characterized by specific translocations,

Correspondence to: Dr Yasushi Fuchimoto, Division of Surgery, Department of Surgical Subspecialities, National Center for Child Health and Development, 2-10-1 Okura, Setagaya-ku, Tokyo 157-8535, Japan

E-mail: fuchimoto-y@ncchd.go.jp

*Contributed equally

Key words: rhabdomyosarcoma, EGFR, cetuximab, actinomycin D i.e., $\mathrm{t}(2 ; 13)(\mathrm{q} 35 ; \mathrm{q} 14)$ in $55 \%$ of cases and $\mathrm{t}(1 ; 13)(\mathrm{p} 36 ; \mathrm{q} 14)$ in $22 \%$ of cases (1). Current treatment options include chemotherapy, complete surgical resection and radiotherapy (3). However, the prognosis for patients with advanced-stage RMS is quite poor (4). The main problems with clinical treatments include metastatic invasion, local tumor recurrence and multidrug resistance. Therefore, more specific, effective and less toxic therapies are required.

Numerous novel anticancer agents are currently in early phase clinical trials. Of these, immunotherapy with specific monoclonal antibodies (mAbs) seems to be a promising approach (5). Alemtuzumab, ibritumomab, rituximab and tositumomab are mAbs already approved for the targeted treatment of white blood cells in leukemia (US Food and Drug Administration). Depending on the level of vascularization, solid tumors may be effectively targeted by bevacizumab, which inhibits vascular endothelial growth factor-A (5).

Identification of the epidermal growth factor receptor (EGFR) as an oncogene has led to the development and approval of panitumumab for the treatment of metastatic colorectal cancer and trastuzumab in breast cancer therapy (5). Cetuximab, a widely used anti-EGFR antibody, consists of a chimeric mouse-human $\mathrm{mAb}$ directed against the extracellular domain of EGFR. Cetuximab has been shown to be particularly effective against colorectal cancer and head and neck cancer (6-9) and works by blocking EGFR, leading to inhibition of cell cycle progression $(10,11)$, angiogenesis, invasion and metastasis (12). Treatment with mAbs increases and activates pro-apoptotic molecules in tumor cells $(11,13)$ and enhances cytotoxicity of topotecan (14). Moreover, cetuximab is able to induce antibody-dependent cell cytotoxicity (ADCC) (15-18) and is therefore suitable for immunotherapeutic use. Potential targets for immunotherapy in RMS are not known. The expression of EGFR has been demonstrated in RMS cell lines and tumors. Moreover, previous studies have shown that EGFR expression is a marker for ERMS, with high sensitivity and specificity.

In the present study, we described the distribution of EGFR in human RMS and evaluated the therapeutic potential of cetuximab in RMS patients exhibiting overexpression of EGFR, investigating whether cetuximab affects EGFR- 
dependent apoptosis and enhances the antitumor activity of currently used chemotherapeutic agents in RMS.

\section{Materials and methods}

Cell culture and reagents. The ERMS cell lines RD (ATCC, Manassas, VA, USA), RMS-YM and KYM-1 and the ARMS cell line Rh30 (DSMZ, Braunschweig, Germany) were cultured in RPMI-1640 medium supplemented with $10 \%$ fetal bovine serum (FBS; Invitrogen, Carlsbad, CA, USA) and $1 \%$ penicillin/streptomycin (Biochrom, Berlin, Germany) in a humidified atmosphere containing $5 \% \mathrm{CO}_{2}$ at $37^{\circ} \mathrm{C}$. All cells were mycoplasma negative. Cetuximab (Erbitux, Merck, Lyon, France) was obtained from Bristol-Myers Squibb Co. Actinomycin D (Cosmegen; Merck \& Co., Inc., Whitehouse Station, NJ, USA) was obtained from Banyu Pharmaceutical Co., Ltd. (Tokyo, Japan).

Flow cytometric analysis. Trypsinized cells were incubated for 30 min in FACS buffer (PBS with 2\% FBS, 2 mM EDTA, $0.005 \% \mathrm{NaN}_{3}$; all reagents were from Sigma-Aldrich, Munich, Germany) containing $10 \mu \mathrm{g} / \mathrm{ml}$ cetuximab (Merck, Darmstadt, Germany). Excess antibodies were washed out with FACS buffer, and cells were labeled with FITC-conjugated goat anti-human IgG (Chemicon, Hofheim, Germany). Data were acquired with a FACSCalibur machine (Becton-Dickinson, Heidelberg, Germany) and analyzed by FlowJo software (Tomy Digital Biology, Co., Ltd., Tokyo, Japan). Controls were acquired using rituximab (Roche, Mannheim, Germany) or by omitting cetuximab. To examine the expression of the differentiation and epithelium marker EGFR in RMS cells, the cells were washed and incubated with mouse monoclonal antibodies targeting EGFR-PE (Becton-Dickinson) for $30 \mathrm{~min}$ at $4^{\circ} \mathrm{C}$. Cells were then washed and counterstained with $1 \mu \mathrm{g} / \mathrm{ml}$ propidium iodide to label the dead cells.

$K$-ras mutation assay. DNA was purified from RMS cells using the DNeasy Blood and Tissue kit (Qiagen, Hilden, Germany). Sample DNA was added to 8 separate reactions. These reaction mixes contained a single primer set specific for either the wild-type sequence or 1 of 7 mutations in codons 12 and 13 . Direct sequencing was conducted using a BigDye Terminator cycle sequencing kit (Applied Biosystems, Foster City, CA, USA) and analyzed on an ABI Prism 310 DNA Analyzer automated sequencer (Applied Biosystems).

Cell viability assay. Cells were plated in 96-well microplates and cultured for $12 \mathrm{~h}$ before exposure to various concentrations of drugs. Cell viability was quantified using the WST-8 assay, determined colorimetrically by measuring the optical density (OD) at a wavelength of $450 \mathrm{~nm}$ using a Rainbow Sunrise (Wako Pure Chemical Industries, Ltd., Osaka, Japan). The concentration resulting in $50 \%$ growth inhibition $\left(\mathrm{IC}_{50}\right)$ was calculated for each treatment condition. Data were analyzed to determine the combination index (CI), a well-established index of the interaction between 2 drugs. CI values of $\langle 1,1$, and $>1$ indicate synergistic, additive and antagonistic effects, respectively.

Determination of combination effects. The effects of actinomycin $\mathrm{D}$ and cetuximab on growth inhibition were determined
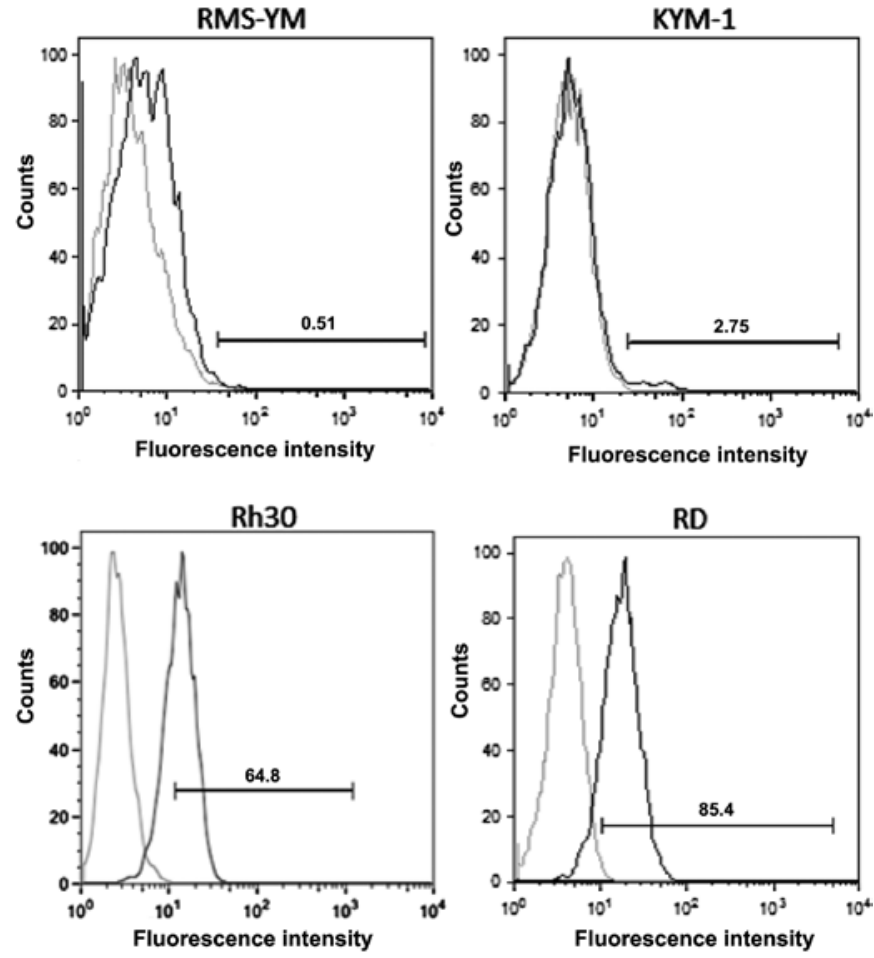

Figure 1. Epidermal growth factor receptor (EGFR) expression analysis in RMS cell lines. High expression of EGFR was detected in RD and Rh30 cells by flow cytometry (black line). The isotype control is also plotted on each panel (gray line).

as described by Chou and Talalay (19). Briefly, the log (fa/fu) was plotted against the concentration for each compound, alone or in combination, where fa was the fraction affected and fu was the fraction unaffected (1-fa) of cells at each concentration. A CI value $<1$ represented synergism between actinomycin D and cetuximab, while values equal to or greater than 1 represented additive and antagonistic effects, respectively. The CI was calculated using the Chou-Talalay method in relation to the fraction of cells affected.

Analysis of apoptosis by flow cytometry. Cell death was determined through Annexin V-FITC/propidium iodide staining using the TACS Annexin V-FITC Apoptosis Detection Kit (R\&D Systems, Minneapolis, MN, USA) according to the manufacturer's instructions. Following incubation, cells were processed as indicated by the manufacturer and analyzed using FITC and propidium iodide detectors in a FACSCalibur flow cytometer (Becton-Dickinson). Data were analyzed in FlowJo software (Tomy Digital Biology).

RNA isolation and real-time PCR. Total RNA was extracted from untreated cells using the RNeasy Micro kit (Qiagen), and cDNA was synthesized using the Transcriptor High Fidelity cDNA Synthesis kit (Roche) according to the manufacturer's instructions. Real-time reverse transcription-PCR was carried out in an ABI PRISM 7300 Real-time PCR system (Applied Biosystems). TaqMan gene expression assay primers and probe mixes were used for glyceraldehyde-3-phosphate dehydrogenase (GAPDH) and EGFR (assay IDs Hs99999905_m1 and Hs01076078_m1, respectively; Applied Biosystems). GAPDH was detected using TaqMan primers and probes and was used 
Table I. Percentage of EGFR-positive cells in the 4 RMS cell lines.

\begin{tabular}{lc}
\hline Cell line & Means \pm SD \\
\hline RD & $70.0 \pm 0.91 \%$ \\
Rh30 & $65.0 \pm 0.78 \%$ \\
KYM-1 & $0.493 \pm 0.066 \%$ \\
RMS-YM & $15.9 \pm 0.32 \%$ \\
\hline
\end{tabular}

Table II. The $\mathrm{IC}_{50}$ values of cetuximab in the 4 RMS cell lines.

\begin{tabular}{lc}
\hline Cell line & $\mathrm{IC}_{50} \mathrm{nM}$ \\
\hline $\mathrm{RD}$ & 5333 \\
$\mathrm{Rh} 30$ & 4697 \\
KYM-1 & 6989 \\
RMS-YM & 9119 \\
\hline
\end{tabular}

Table III. Combination index values determined for cetuximabactinomycin D combinations for the 4 RMS cell lines.

\begin{tabular}{lc}
\hline Cell line & Combination index \\
\hline RD & 0.774 \\
Rh30 & 0.789 \\
KYM-1 & 1.265 \\
RMS-YM & 1.072 \\
\hline
\end{tabular}

as the control gene. The thermal cycling reaction included incubation at $95^{\circ} \mathrm{C}$ for $10 \mathrm{~min}$ and 40 cycles of $95^{\circ} \mathrm{C}$ for $15 \mathrm{sec}$ and $60^{\circ} \mathrm{C}$ for $60 \mathrm{sec}$. Relative target mRNA expression was determined using the $\Delta \Delta \mathrm{Ct}$ method (value obtained by subtracting the $\mathrm{Ct}$ value of GAPDH mRNA from the $\mathrm{Ct}$ value of the target mRNA). Data were calculated as the ratio of target mRNA to GAPDH mRNA using the $2^{-\Delta \Delta C t}$ method (20).

Statistical analysis. Determination of the statistical significance of differences between the gene expression analysis groups was carried out using the Student's t-tests in GraphPad Prism 4.00 software (GraphPad Software Inc., La Jolla, CA, USA). All numeric data are expressed as the means \pm SD. P-values $<0.05$ were considered to indicate statistically significant differences.

\section{Results}

Expression of EGFR and mutational status of K-ras. The RD and Rh30 cell lines had a large number of EGFR-positive cells, whereas the KYM-1 and RMS-YM cell lines had a small number of EGFR-positive cells (Fig. 1, Table I). Real-time PCR analyses showed that EGFR was overexpressed by 9.62 \pm 1.36 - and 3.09 \pm 1.93 -fold in RD and Rh30 cells, respectively, compared with RMS-YM cells; EGFR was not detected

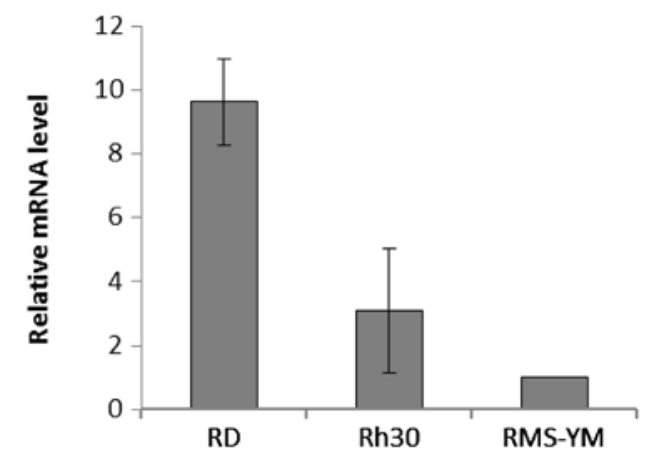

Figure 2. Expression of the EGFR gene as measured by real-time quantitative PCR. The results are shown as fold induction relative to RMS-YM cells (EGFR was not detected in KYM-1 cells).

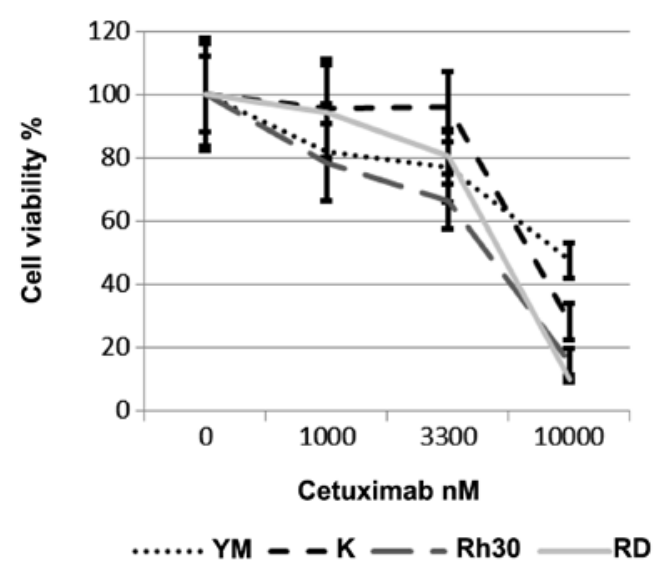

Figure 3. RMS cells were incubated with the indicated cetuximab concentrations for $72 \mathrm{~h}$, and cell viability was measured by WST- 8 assay.

in KYM-1 cells in this assay (Fig. 2). Collectively, these data suggest that EGFR is predominantly expressed in RD and Rh30 cells. Sequencing of full-length cDNAs revealed no mutations in codons 12 and 13 of K-ras, suggesting that all 4 RMS cell lines expressed wild-type K-ras (data not shown).

Cetuximab inhibits cell growth in RMS cell lines. Next, we examined the effects of cetuximab on the growth of RMS cells. Cetuximab dose-dependently inhibited the growth of all 4 RMS cell lines, regardless of their EGFR-expression status (Fig. 3). The $\mathrm{IC}_{50}$ values of cetuximab in these 4 cell lines were $4.7 \mu \mathrm{M}$ (Rh30), 5.3 $\mu \mathrm{M}$ (RD), $9.1 \mu \mathrm{M}$ (RMS-YM) and $7.0 \mu \mathrm{M}$ (KYM-1) (Table II). $\mathrm{IC}_{50}$ value were lower in EGFR-positive cells.

Cetuximab enhances actinomycin D-dependent cytotoxicity in RMS cell lines expressing high levels of EGFR. Incubation with $2 \mu \mathrm{mol} / 1$ cetuximab alone had only a slight effect on the viability of the 4 RMS cell lines, while combination treatment with cetuximab and actinomycin D enhanced drug-induced cytotoxicity in EGFR-amplified cell lines (Fig. 4). This combination effect was synergistic for cetuximab and actinomycin D in RD and Rh30 cells, with CI values $<1.0$ for both cell lines. By contrast, the combination effect was antagonistic for cetuximab and actinomycin D in RMS-YM and KYM-1 cells, with CI values >1.0 (Table III). Moreover, combination 

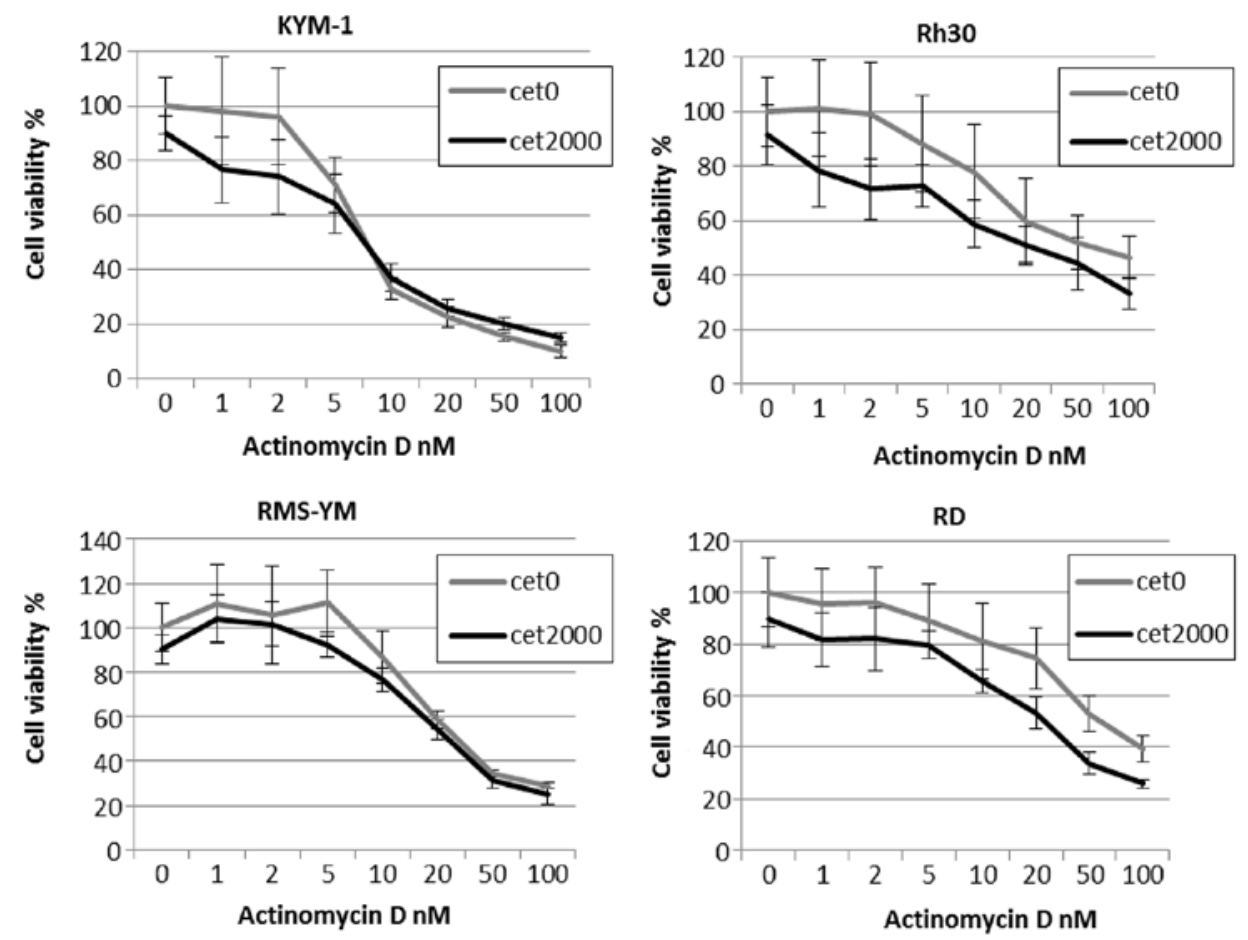

Figure 4. RMS cells were incubated with increasing concentrations of actinomycin D alone (gray line; cet0) or in combination with $2 \mu \mathrm{M}$ cetuximab (black line; cet2000) for $72 \mathrm{~h}$. Cell viability was assessed by WST- 8 assay.
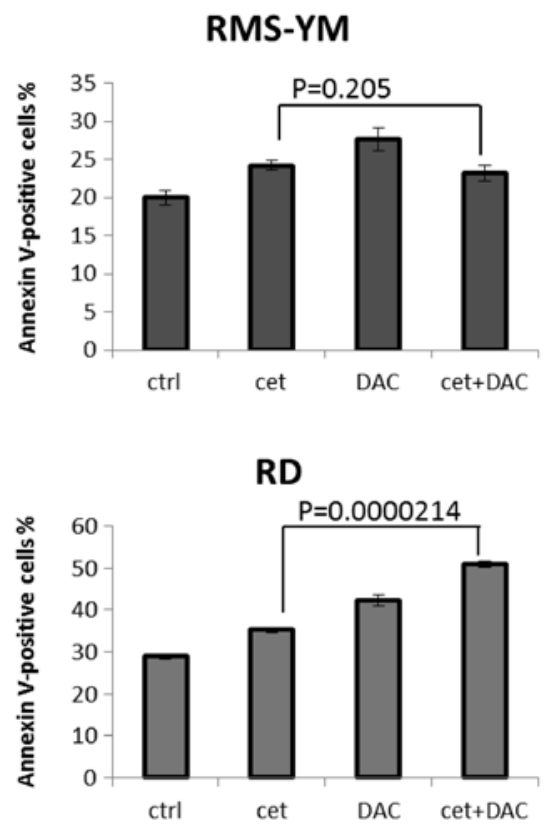

Figure 5. Effects of cetuximab in combination with actinomycin D on RMS cell viability. Viability was assessed by Annexin V-FITC/propidium iodide staining and was measured by flow cytometry. Cells were treated with cetuximab at doses of $\mathrm{IC}_{50}$ (RMS-YM; $9119 \mathrm{nM}, \mathrm{RD} ; 5333 \mathrm{nM}$, respectively), actinomycin $\mathrm{D}$ at doses of $\mathrm{IC}_{50}$ (RMS-YM, $40 \mathrm{nM} ; \mathrm{RD}, 10 \mathrm{nM}$, respectively), or combination cetuximab and actinomycin D for $72 \mathrm{~h}$.

treatment with cetuximab and actinomycin D induced apoptosis in EGFR-positive RMS cells. At $72 \mathrm{~h}$ after treatment, a greater number of Annexin V-positive cells were detected in RD cells treated with both cetuximab and actinomycin $\mathrm{D}$ than in RD cells treated with cetuximab alone $(\mathrm{P}=0.000214$, $\mathrm{t}$-test, statistical significance). The increased apoptosis induced by treatment with these 2 agents was less pronounced in RMS-YM cells than when treated with cetuximab alone $(\mathrm{P}=0.205$, $\mathrm{t}$-test, not significant) (Fig. 5).

\section{Discussion}

Although inhibition of EGFR has shown promise as a potential therapeutic treatment in several epithelial malignancies, little is known about its effect on soft tissue tumors. The largest case series reported in the literature demonstrated positive EGFR staining in $60 \%$ of human adult soft tissue tumors $(n=281)(21)$. Studies in RMS have shown that expression of EGFR correlates with embryonal subtype (22). It is well established that embryonal subtypes generally behave less aggressively than alveolar subtypes. However, despite advances in the treatment of RMS, the overall 5-year failure-free survival rate does not exceed $80 \%$, even among patients with ERMS or early-stage disease. Novel approaches for the treatment of RMS are required. In the present study, we chose cetuximab, an mAB targeting EGFR that has already been approved for therapeutic applications.

Array-based analysis revealed higher expression of several genes, including BCL2L1 (23), CNR1 (24), CXCR4 (25), MET (26), MYCN (27,28), PDGFR-A (29) and TFAP2( $\beta)(30,31)$, in ARMS compared with ERMS. Conversely, EGFR (28), HMGA2 (26) and YB-1 (32) were upregulated in ERMS. Of these gene products, CNR1, CXCR4, MET, PDGFR-A and EGFR are localized to the cell membrane and may function as targets for therapeutic antibodies. Our results showed that one ERMS and one ARMS cell line, RD and Rh30, have high EGFR protein expression assessed by flow cytometry, and high expression at the mRNA level by real-time PCR, as previously reported (33). 
Mutations in K-ras, which have been reported to occur in colorectal cancer, are responsible for cetuximab resistance in tumor cells. Prior to treatment with cetuximab, K-ras mutations must be monitored (34). However, in a study of RMS tissues, in which a response to blocking antibodies such as cetuximab could be expected, K-ras mutations were detected in only 2 out of 38 ERMS tissues and in no ARMS tissues $(n=12)(35)$. Additionally, RD cells contain only an NRAS mutation (36), and our data showed no mutations in K-ras for RD, RH30, KYM-1 and RMS-YM cells. Although mutations in K-ras are rare in RMS, K-ras mutations should be evaluated prior to treatment for effective treatment with cetuximab.

Actinomycin D is used in current standard treatments for RMS, in combination with vincristine and cyclophosphamide. Herrmann et al (33) reported that cell-dependent cytotoxicity of peripheral blood mononuclear cells to RD and Rh30 was enhanced specifically by cetuximab. Herein, we evaluated the treatment effects of cetuximab alone as well as the combination with cetuximab and antitumor reagent. A low concentration of cetuximab in combination with actinomycin D had an enhanced antitumor effect. The combination with cetuximab and actinomycin D was synergistic in inhibiting cell growth, and inducing cell apoptosis, with a CI of $<1$ in EGFR amplified cells, RD and Rh30. By contrast, the combination was antagonistic in RMS cells without EGFR amplified, with a CI of $>1$. Apoptotic cells without EGFR amplified RMS, treated with cetuximab and actinomycin D, were fewer than those treated with actinomycin D alone (Fig. 5), suggesting that the combination of cetuximab and standard chemotherapy including actinomycin D may be a promising therapeutic strategy for patients with EGFR amplified RMS, but not for patients without EGFR amplified RMS. Previous studies reported that activation of EGFR leads to downstream signaling that activates mitogenic and survival pathways, such as the MAPK and Pi3-K/AKT pathways (37). Inhibition of these pathways by an EGFR antagonist, such as cetuximab, can lead to induction of apoptosis and anti-proliferative effects (38). These results suggest that combination therapy may block the signaling pathways downstream of EGFR.

In summary, we have shown that combination of cetuximab and actinomycin D resulted in antitumor activity against human RMS cell lines expressing high levels of EGFR, suggesting that EGFR antagonists may be promising therapeutic interventions for the treatment of RMS. Further animal studies and clinical trials are required to evaluate the safety of EGFR antagonists.

\section{Acknowledgements}

The RMS cell lines were a kind gift from Dr Junko Takita (Department of Pediatrics, Graduate School of Medicine, University of Tokyo, Tokyo, Japan) and Dr Hajime Hosoi (Department of Pediatrics, Graduate School of Medical Science, Kyoto Prefectural University of Medicine, Kyoto, Japan). This study was supported by a grant-in-aid for young scientists (B) from the Ministry of Education, Culture, Sports, Science and Technology (MEXT), Japan.

\section{References}

1. McDowell HP: Update on childhood rhabdomyosarcoma. Arch Dis Child 88: 354-357, 2003.

2. Pappo AS, Shapiro DN, Crist WM and Maurer HM: Biology and therapy of pediatric rhabdomyosarcoma. J Clin Oncol 13: 2123-2139, 1995.

3. Wolden SL, Anderson JR, Crist WM, Breneman JC, Wharam MD Jr, Wiener ES, Qualman SJ and Donaldson SS: Indications for radiotherapy and chemotherapy after complete resection in rhabdomyosarcoma: a report from the Intergroup Rhabdomyosarcoma Studies I to III. J Clin Oncol 17: 3468-3475, 1999.

4. Koscielniak E, Morgan M and Treuner J: Soft tissue sarcoma in children: prognosis and management. Paediatr Drugs 4: 21-28, 2002.

5. Ma WW and Adjei AA: Novel agents on the horizon for cancer therapy. CA Cancer J Clin 59: 111-137, 2009.

6. Capdevila J,Elez E, Macarulla T, Ramos FJ, Ruiz-Echarri M and Tabernero J: Anti-epidermal growth factor receptor monoclonal antibodies in cancer treatment. Cancer Treat Rev 35: 354-363, 2009.

7. Cunningham D, Humblet Y, Siena S, Khayat D, Bleiberg H, Santoro A, Bets D, Mueser M, Harstrick A, Verslype C, Chau I and Van Cutsem E: Cetuximab monotherapy and cetuximab plus irinotecan in irinotecan-refractory metastatic colorectal cancer. N Engl J Med 351: 337-345, 2004.

8. Herbst RS, Arquette M, Shin DM, Dicke K, Vokes EE, Azarnia N, Hong WK and Kies MS: Phase II multicenter study of the epidermal growth factor receptor antibody cetuximab and cisplatin for recurrent and refractory squamous cell carcinoma of the head and neck. J Clin Oncol 23: 5578-5587, 2005.

9. Vermorken JB: Squamous cell carcinoma of the head and neck. J BUON 7: 311-317, 2002.

10. Peng D, Fan Z, Lu Y, DeBlasio T, Scher H and Mendelsohn J: Anti-epidermal growth factor receptor monoclonal antibody 225 up-regulates $27^{\mathrm{KIPl}}$ and induces $\mathrm{G}_{1}$ arrest in prostatic cancer cell line DU145. Cancer Res 56: 3666-3669, 1996.

11. Wu X, Fan Z, Masui H, Rosen N and Mendelsohn J: Apoptosis induced by an anti-epidermal growth factor receptor monoclonal antibody in a human colorectal carcinoma cell line and its delay by insulin. J Clin Invest 95: 1897-1905, 1995.

12. Perrotte P, Matsumoto T, Inoue K, Kuniyasu K, Eve BY, Hicklin DJ, Radinsky R and Dinney CPN: Anti-epidermal growth factor receptor antibody $\mathrm{C} 225$ inhibits angiogenesis in human transitional cell carcinoma growing orthotopically in nude mice. Clin Cancer Res 5: 257-265, 1999.

13. Liu B, Fang M, Lu Y, Mendelsohn J and Fan Z: Fibroblast growth factor and insulin-like growth factor differentially modulate the apoptosis and G1 arrest induced by anti-epidermal growth factor receptor monoclonal antibody. Oncogene 20: 1913-1922, 2001.

14. Ciardiello F, Bianco R, Damiano V, De Lorenzo S, Pepe S, De Placido S, Fan Z, Mendelsohn J, Bianco AR and Tortora G: Antitumor activity of sequential treatment with topotecan and anti-epidermal growth factor receptor monoclonal antibody C225. Clin Cancer Res 5: 909-916, 1999.

15. Kawaguchi Y, Kono K, Mimura K, Sugai H, Akaike H and Fujii H: Cetuximab induce antibody-dependent cellular cytotoxicity against EGFR-expressing esophageal squamous cell carcinoma. Int J Cancer 120: 781-787, 2007.

16. Kimura H, Sakai K, Arao T, Shimoyama T, Tamura T and Nishio K: Antibody-dependent cellular cytotoxicity of cetuximab against tumor cells with wild-type or mutant epidermal growth factor receptor. Cancer Sci 98: 1275-1280, 2007.

17. Kurai J, Chikumi H, Hashimoto K, Yamaguchi K, Yamasaki A, Sako T, Touge H, Makino H, Takata M, Miyata M, Nakamoto M, Burioka N and Shimizu E: Antibody-dependent cellular cytotoxicity mediated by cetuximab against lung cancer cell lines. Clin Cancer Res 13: 1552-1561, 2007.

18. Naramura M, Gillies SD, Mendelsohn J, Reisfeld RA and Mueller BM: Therapeutic potential of chimeric and murine anti(epidermal growth factor receptor) antibodies in a metastasis model for human melanoma. Cancer Immunol Immunother 37: 343-349, 1993.

19. Chou TC and Talalay P: Quantitative analysis of dose-effect relationships: the combined effects of multiple drugs or enzyme inhibitors. Adv Enzyme Regul 22: 27-55, 1984.

20. Livak KJ and Schmittgen TD: Analysis of relative gene expression data using real-time quantitative PCR and the 2(-Delta Delta C(T)) method. Methods 25: 402-408, 2001. 
21. Sato O, Wada T, Kawai A, Yamaguchi U, Makimoto A, Kokai Y, Yamashita T, Chuman H, Beppu Y, Tani Y and Hasegawa T: Expression of epidermal growth factor receptor, ERBB2 and KIT in adult soft tissue sarcomas: a clinicopathologic study of 281 cases. Cancer 103: 1881-1890, 2005.

22. Ganti R, Skapek SX, Zhang J, Fuller CE, Wu J, Billups CA, Breitfeld PP, Dalton JD, Meyer WH and Khoury JD: Expression and genomic status of EGFR and ErbB-2 in alveolar and embryonal rhabdomyosarcoma. Mod Pathol 19: 1213-1220, 2006.

23. Margue CM, Bernasconi M, Barr FG and Schäfer BW: Transcriptional modulation of the anti-apoptotic protein BCL-XL by the paired box transcription factors PAX3 and PAX3/FKHR Oncogene 19: 2921-2929, 2000.

24. Laé M, Ahn EH, Mercado GE, Chuai S, Edgar M, Pawel BR, Olshen A, Barr FG and Ladanyi M: Global gene expression profiling of PAX-FKHR fusion-positive alveolar and PAX-FKHR fusion-negative embryonal rhabdomyosarcomas. J Pathol 212: 143-151, 2007.

25. Tomescu O, Xia SJ, Strezlecki D, Bennicelli JL, Ginsberg J, Pawel B and Barr FG: Inducible short-term and stable long-term cell culture systems reveal that the PAX3-FKHR fusion oncoprotein regulates CXCR4, PAX3, and PAX7 expression. Lab Invest 84: 1060-1070, 2004

26. Taulli R, Scuoppo C, Bersani F, Accornero P, Forni PE, Miretti S, Grinza A, Allegra P, Schmitt-Ney M, Crepaldi T and Ponzetto C: Validation of Met as a therapeutic target in alveolar and embryonal rhabdomyosarcoma. Cancer Res 66: 4742-4749, 2006.

27. Mercado GE, Xia SJ, Zhang C, Ahn EH, Gustafson DM, Laé M, Ladanyi $M$ and Barr FG: Identification of PAX3-FKHR-regulated genes differentially expressed between alveolar and embryonal rhabdomyosarcoma: focus on MYCN as a biologically relevant target. Genes Chromosomes Cancer 47: 510-520, 2008.

28. Williamson D, Lu YJ, Gordon T, Sciot R, Kelsey A, Fisher C, Poremba C, Anderson J, Pritchard-Jones K and Shipley J: Relationship between MYCN copy number and expression in rhabdomyosarcomas and correlation with adverse prognosis in the alveolar subtype. J Clin Oncol 23: 880-888, 2005.

29. Taniguchi E, Nishijo K, McCleish AT, Michalek JE, Grayson MH, Infante AJ, Abboud HE, Legallo RD, Qualman SJ, Rubin BP and Keller C: PDGFR-A is a therapeutic target in alveolar rhabdomyosarcoma. Oncogene 27: 6550-6560, 2008.
30. Davicioni E, Anderson MJ, Finckenstein FG, Lynch JC, Qualman SJ, Shimada H, Schofield DE, Buckley JD, Meyer WH, Sorensen PHB and Triche TJ: Molecular classification of rhabdomyosarcoma - genotypic and phenotypic determinants of diagnosis: a report from the Children's Oncology Group. Am J Pathol 174: 550-564, 2009.

31. Ebauer M, Wachtel M, Niggli FK and Schäfer BW: Comparative expression profiling identifies an in vivo target gene signature with TFAP2B as a mediator of the survival function of PAX3/FKHR. Oncogene 26: 7267-7281, 2007.

32. Oda Y, Kohashi K, Yamamoto H, Tamiya S, Kohno K, Kuwano M, Iwamoto Y, Tajiri T, Taguchi T and Tsuneyoshi M: Different expression profiles of Y-box-binding protein-1 and multidrug resistance-associated proteins between alveolar and embryonal rhabdomyosarcoma. Cancer Sci 99: 726-732, 2008.

33. Herrmann D, Seitz G, Warmann SW, Bonin M, Fuchs J and Armeanu-Ebinger S: Cetuximab promotes immunotoxicity against rhabdomyosarcoma in vitro. J Immunother 33: 279-286, 2010.

34. Lièvre A, Bachet J-B, Le Corre D, Boige V, Landi B, Emile JF, Côté JF, Tomasic G, Penna C, Ducreux M, Rougier P, PenaultLlorca F and Laurent-Puig P: KRAS mutation status is predictive of response to cetuximab therapy in colorectal cancer. Cancer Res 66: 3992-3995, 2006.

35. Wellcome Trust Sanger Institute: Catalogue of Somatic Mutations in Cancer. http://www.sanger.ac.uk/genetics/CGP/ cosmic/. Accessed June 4, 2012.

36. Chen Y, Takita J, Hiwatari M, Igarashi T, Hanada R, Kikuchi A, Hongo T, Taki T, Ogasawara M, Shimada A and Hayashi Y: Mutations of the PTPN11 and RAS genes in rhabdomyosarcoma and pediatric hematological malignancies. Genes Chromosomes Cancer 45: 583-591, 2006.

37. Bancroft CC, Chen Z, Yeh J, Sunwoo JB, Yeh NT, Jackson S, Jackson C and Van Waes C: Effects of pharmacologic antagonists of epidermal growth factor receptor, PI3K and MEK signal kinases on NF-kappaB and AP-1 activation and IL-8 and VEGF expression in human head and neck squamous cell carcinoma lines. Int J Cancer 99: 538-548, 2002.

38. Raymond E, Faivre S and Armand JP: Epidermal growth factor receptor tyrosine kinase as a target for anticancer therapy. Drugs 60 (Suppl 1): 15-23, 2000. 